\title{
The Biodiversity Heritage Library: Empowering Discovery through Free Access to Biodiversity Knowledge
}

\author{
Martin R. Kalfatovic and Grace Costantino \\ Biodiversity Heritage Library, Smithsonian Libraries, Washington, DC, US \\ Corresponding author: Grace Costantino (CostantinoG@si.edu)
}

The advancement of knowledge about life on the planet-its origins, preservation, and loss of species and environments-is dependent on access and reference to library collections. The Biodiversity Heritage Library ( $\mathrm{BHL}$ ) is a global digital library that serves the biodiversity research community, as well as a widening circle of those interested in learning more about life. Through an international consortium of natural history and botanical libraries and in close collaboration with researchers, bioinformaticians, publishers, and information technology professionals, BHL has democratized access to biodiversity information and revolutionized research worldwide, allowing everyone, everywhere to study and explore life on Earth.

Keywords: biodiversity; open access; open data; natural history; digital libraries; science

Writing in support of the natural history collections then at the British Museum, Charles Darwin and his colleagues from the British Society for the Advancement of Science (and of various other scientific societies) noted that 'the cultivation of natural science cannot be efficiently carried on without reference to an extensive library' (Darwin et al. 1847). The advancement of knowledge about life on the planet-its origins, preservation, and loss of species and environments-is no less dependent on access and reference to library collections. The global nature of biodiversity research, the expansion of natural history research into new areas such as genomics, and the digitization of specimen collections and ancillary data call not just for an extensive library, but for a library that researchers and citizen scientists can use anytime, anywhere.

The Biodiversity Heritage Library (BHL), established in 2006, is a global digital library that serves the biodiversity research community, as well as a widening circle of those interested in learning more about life. As an international consortium of over 40 Members and Affiliates and more than 80 partner contributors, BHL currently provides access to over 229 thousand volumes comprising over 54 million pages. Importantly, BHL is not just a legacy collection; it truly represents our biodiversity heritage with publications from the fifteenth century through to the present day, the latter volumes obtained with the permission of the intellectual property holders.

With its close collaboration of librarians, researchers, bioinformaticians, publishers, and information technology professionals, the Biodiversity Heritage Library stands out not only in its service to its own partners, but also in its collaborative approach with the wider library community and openness in making content and data available to users worldwide. From its early use of crowd-sourcing for tagging illustrations to its innovative design of digitization workflows and implementation of new online descriptive standards, BHL is a key contributor to the world of global digital library development.

BHL has changed the lives of researchers. An environmental scientist completes an article in a fraction of the time it would have taken before. An African botanist compares a specimen's published description to field notes on its collecting history. By facilitating the daily work of biodiversity research, BHL provides a global network of researchers with an easy-to-use digital library of content and services. Large taxonomic databases also use BHL, 
including specialized databases such as Tropicos (botany) and the World Register of Marine Species and major aggregators such as the Global Biodiversity Information Facility (GBIF) and the Encyclopedia of Life (EOL). BHL is also a valuable and used resource for Wikipedians. In sharing over 120,000 life science illustrations through Flickr, BHL has expanded its audience to include people from the worlds of art and design.

Using a range of social media tools, BHL has connected with a worldwide audience to build a passionate, vocal community of followers who regularly express their adoration for the library. As one Facebook follower shared, " $[\mathrm{t}]$ he Biodiversity Heritage Library is one of the greatest treasures on the internet, if you are into natural history, taxonomy, the history of natural history etc. I couldn't do the work I do without it.' Likewise, a Flickr enthusiast wrote, '[t]his incredible collection of images of the world's biodiversity will give you chills ... thanks to the hard work of @BioDivLibrary.'

To build and maximize capacity across partners, BHL provides intensive workshops on strategies for contributing content. In The Best of Both Worlds, former Smithsonian Secretary G. Wayne Clough notes that BHL is ' [a]n impressive example of what can be accomplished by digitization of library resources through a collaborative approach' $(2013,43)$. This highly collaborative approach serves BHL's users with a constantly growing collection of open-access biodiversity literature, including materials often physically available only in limited locations throughout the world. Each month, more than 118,000 visitors benefit from this improved access. Users frequently submit enthusiastic testimonials. As one user shared via email: "BHL ... provides access to historical material ... that logistically and time-wise would otherwise prove very difficult if not impossible to find and access...."

A signatory of the Bouchout Declaration, BHL's commitment to open access extends beyond making scanned pages available through BHL. Content is available via Internet Archive, the Digital Public Library of America, and Europeana, and BHL's suite of APIs brings BHL data directly to users.

Factors such as collaboration and openness support the vision of BHL: 'Inspiring discovery through free access to biodiversity knowledge.' And it is this discovery that makes BHL a cornerstone of the larger library of life as described by Dr. Richard Pyle (Hawaii Biological Survey, Bernice P. Bishop Museum):

When we do taxonomy and systematics.... We are building the card catalog for the most important library that has ever existed, and ever will exist (at least from the perspective of humans).... When we stomp through the forests and swim over the reefs collecting our specimens, we are gathering a few precious copies of those books and storing them in the vaults of our natural history museums where (with luck and funding), the information they contain will persist beyond the time when no more copies exist in nature. Unlike physics; unlike chemistry; unlike geology; the clock is ticking on our ability to capture this information before it's gone. Forever. (Pyle 2010)

Furthermore, in many cases, the only evidence for now-extinct species are in the descriptions and illustrations made available by BHL. Building on the work of librarians and the collections amassed in their libraries for more than 200 years, BHL gives, as Dr. Leigh Anne Riedman (Department of Earth and Planetary Sciences, Harvard University) terms it, 'the gift of my own time' (Kalfatovic 2017). By providing open access to global library collections, the Biodiversity Heritage Library gives researchers the time and information they need to pursue research that may help save the precious volumes of life on the planet.

\section{Acknowledgements}

This work was supported by the Smithsonian Institution.

\section{Competing Interests}

The authors have no competing interests to declare.

\section{References}

Clough, G. Wayne. 2013. Best of Both Worlds: Museums, Libraries, and Archives in the Digital Age. Washington, DC: Smithsonian Institution. DOI: https://doi.org/10.5479/si.9780981950013

Darwin, C. R., et al. 1847. "Copy of Memorial to the First Lord of the Treasury [Lord John Russell], respecting the Management of the British Museum." Parliamentary Papers, Accounts and Papers paper number (268), XXXIV(253): 1-3. 13 April. The Complete Work of Charles Darwin Online, John van Wyhe (ed.), 2002-. http://darwin-online.org.uk/content/frameset?itemID=F1831\&viewtype=side\&pageseq=1. 
Kalfatovic, Martin R. 2017. “The Gift of Time': Impact through Open: The Biodiversity Heritage Library." Presentation at the "Bracing for Impact: Digitizing Collections to Change Lives" Smithsonian Digitization Fair. Washington, DC, October 19, 2017. https://www.slideshare.net/Kalfatovic/the-gift-of-time-impactthrough-open-the-biodiversity-heritage-library.

Pyle, Richard L. 2010. "[Taxacom] Was Reproducibility of phylogenetic analysis." TAXACOM Listserv, January 27. http://mailman.nhm.ku.edu/pipermail/taxacom/2010-January/115214.html.

How to cite this article: Kalfatovic, Martin R. and Grace Costantino. 2018. The Biodiversity Heritage Library: Empowering Discovery through Free Access to Biodiversity Knowledge. KULA: knowledge creation, dissemination, and preservation studies 2(1): 17. DOI: https://doi.org/10.5334/kula.41

Submitted: 22 May 2018 Accepted: 11 July 2018 Published: 29 November 2018

Copyright: ( 2018 The text of this article is authored by employees of the United States Government and therefore is not subject to copyright protection and is in the public domain. This is an open-access article distributed under the terms of the Creative Commons Attribution 4.0 International License (CC-BY 4.0), which permits unrestricted use, distribution, and reproduction in any medium, provided the original author and source are credited. See http://creativecommons.org/licenses/by/4.0/.

$\mathrm{lu}[\quad$ KULA: knowledge creation, dissemination, and preservation studies is a peer-reviewed open access journal published by Ubiquity Press 